\title{
Response of Ancestral Soybean Lines and Commercial Cultivars to Rhizoctonia Root and Hypocotyl Rot
}

\author{
C. A. Bradley, Department of Crop Sciences, G. L. Hartman and R. L. Nelson, USDA Agricultural Research Ser- \\ vice and Department of Crop Sciences, D. S. Mueller and W. L. Pedersen, Department of Crop Sciences, Univer- \\ sity of Illinois, National Soybean Research Laboratory, 1101 W. Peabody Dr., Urbana 61801
}

\begin{abstract}
Bradley, C. A., Hartman, G. L., Nelson, R. L., Mueller, D. S., and Pedersen, W. L. 2001. Response of ancestral soybean lines and commercial cultivars to Rhizoctonia root and hypocotyl rot. Plant Dis. 85:1091-1095.

Rhizoctonia root and hypocotyl rot is a common disease of soybean caused by Rhizoctonia solani. There are no commercial cultivars marketed as resistant to Rhizoctonia root and hypocotyl rot, and only a few sources of partial resistance to this disease have been reported. Ninety ancestral soybean lines, maturity groups (MGs) 000 to X, and 700 commercial cultivars, MGs II to IV, were evaluated for resistance to $R$. solani under greenhouse conditions. Most of the ancestral lines and cultivars evaluated were susceptible; however, 21 of the ancestral lines and 20 of the commercial cultivars were partially resistant. Of the 21 ancestral lines, CNS, Mandarin (Ottawa), and Jackson are in the pedigree of cultivars previously reported as being partially resistant to $R$. solani. In an additional study, dry root weights of 21 soybean cultivars were evaluated after inoculation with $R$. solani. Variation in dry root weight occurred among cultivars, but there was not a significant $(P=0.05)$ correlation between dry root weight and disease severity.
\end{abstract}

Rhizoctonia root and hypocotyl rot of soybean (Glycine max (L.) Merr.), caused by Rhizoctonia solani Kühn (teleomorph Thanatephorus cucumeris (A.B. Frank) Donk), is a common and widespread soilborne disease that causes damping-off as well as lesions on the hypocotyl and root (27). Wrather et al. (25) estimated that Rhizoctonia and Pythium root rots caused a combined soybean yield reduction of 108,000 metric tons for the top 10 soybean producing countries in 1994. Tachibana et al. (24) reported that $R$. solani reduced soybean yield as much as $48 \%$ in small plots.

There are no commercial cultivars that are marketed as having resistance to $R$. solani, and few reports have been published on evaluation of soybean for resis-

Corresponding author: W. L. Pedersen E-mail: wpederse@uiuc.edu

Mention of a trademark or proprietary product does not constitute a guarantee or warranty of the product by the U.S. Department of Agriculture or the University of Illinois and does not imply its approval to the exclusion of other products that may also be suitable.

Current address of C. A. Bradley: Department of Plant, Soil, and Entomological Sciences, University of Idaho, Kimberly Research and Extension Center, 3793 N. 3600 E., Kimberly, ID 83341.

Accepted for publication 15 June 2001.

Publication no. D-2001-0725-01R

(C) 2001 The American Phytopathological Society tance to $R$. solani. Cardoso et al. (3) evaluated 39 cultivars and plant introductions (PIs) of soybean for resistance to an isolate of $R$. solani, anastomosis group (AG) 4, and found all entries to be as susceptible as Chippewa 64, the susceptible check. Lewis and Papavizas (10) found variation among soybean cultivars for susceptibility to $R$. solani (AG unknown), with Delmar and Hood being the least susceptible of eight cultivars evaluated. Muyolo et al. (15) evaluated 15 soybean cultivars for resistance to two isolates of $R$. solani (AG 2-2 and $A G$ 4) and reported a resistant root reaction and a partially resistant hypocotyl reaction for Asgrow 7986, Centennial, Hardee, Pella, RA 606, and Vickery.

The objective of this study was to evaluate the ancestral soybean lines from which current North American cultivars were developed, as well as privately and publicly developed commercial soybean cultivars, for resistance to $R$. solani, and to identify sources of resistance that could be used immediately by growers and breeders to manage the disease.

\section{MATERIALS AND METHODS}

Inoculum production, soybean inoculations, and disease rating. $R$. solani isolate 65L-2 (ATCC 66489 and AG 2-2), originally isolated from soybean in Illinois (11), was stored on $1.5 \%$ water agar at $5^{\circ} \mathrm{C}$. To initiate inoculum production, a 5mm-diameter plug of the $R$. solani culture was transferred to a 9-cm-diameter petri dish containing potato dextrose agar (PDA, Difco Laboratories, Detroit, MI) and incu- bated at $25^{\circ} \mathrm{C}$ with 12 -h light/dark cycles. After 2 days, a 5-mm-diameter plug was taken from the edge of the growing colony hyphal tip and transferred to a 9-cmdiameter petri dish containing PDA. The plates were incubated at $25^{\circ} \mathrm{C}$ with $12-\mathrm{h}$ light/dark cycles. After 5 days of growth, the agar and fungal cultures from five petri dishes were macerated in 1 liter of distilled water for 1 min using a Waring commercial blender (Waring Products Corporation, New York). The mycelial suspension was adjusted to approximately $1.53 \times 10^{4}$ CFU per ml. When soybean plants were at growth stage VE (7), two holes approximately $0.5 \mathrm{~cm}$ diameter and $2 \mathrm{~cm}$ deep were made in the soil around each soybean hypocotyl with a wooden dowel. A syringe was used to apply $2 \mathrm{ml}$ of the mycelial suspension on and around the hypocotyl using a method similar to that of Wrona et al. (26). The holes in the soil around the hypocotyl allowed the mycelial suspension to flow down to the roots. This method was used to inoculate seedlings with $R$. solani in all of the studies reported in this article.

After 18 to 21 days, when there was an obvious difference in disease severity between the susceptible and partially resistant check cultivars, plants were removed from trays. Soil was removed from the roots by washing with running tap water, and the roots and hypocotyl of each plant were evaluated using the scale developed by Cardoso and Echandi (2) where: $0=$ no lesions, $1=$ lesions $<2.5 \mathrm{~mm}, 2=$ lesions 2.5 to $5 \mathrm{~mm}, 3=$ lesions $>5 \mathrm{~mm}, 4=$ lesions girdling the plant and leaves wilting, and $5=$ seedling damped-off or dead.

Ancestral lines. Ninety ancestral soybean lines, maturity groups (MG) 000 to $\mathrm{X}$, which represent approximately $99 \%$ of the germ plasm used to develop modern North American soybean cultivars (8), were obtained from the USDA National Soybean Germplasm Collection (Urbana, IL) and inoculated with $R$. solani in the greenhouse as previously described. Five seeds of each line were planted in $50 \times 35$ $\times 10 \mathrm{~cm}$ trays containing a steampasteurized potting mixture that consisted of a 2:1 ratio of sand to a silt loam soil, respectively. Each tray contained 20 lines and a partially resistant or susceptible check cultivar. The susceptible check was Jack, and the partially resistant checks were Centennial (15) or Savoy (C. A. 
Bradley and W. L. Pedersen, unpublished data). Each check was included a minimum of five times. After inoculation, plants were placed on a greenhouse bench and grown under a 16-h photoperiod. The photosynthetically active radiation (PAR) was measured to be $434 \mu \mathrm{E} \cdot \mathrm{m}^{-2} \cdot \mathrm{s}^{-1}$ (LI-170 Quantum/Radiometer/Photometer, Lambda Instrument Corp., Lincoln, NE). Day and night temperatures were $24 \pm 3^{\circ} \mathrm{C}$. Plants were watered to saturation after planting and maintained at near field capacity throughout the study. Ancestral lines were arranged in a randomized complete block (RCB) design with three replications and the study was repeated.

Thirty-eight of the most resistant lines, plus the check cultivars, Jack, Centennial, and Savoy, were re-evaluated for resistance to $R$. solani. These 38 lines were selected because they were not significantly $(P=$ 0.05 ) different from the partially resistant check, Centennial, in the initial evaluation. Inoculations and ratings were done as previously described with three replications and the study was repeated.

Table 1. Analyses of variance for screening ancestral soybean line entries and screening commercial soybean cultivar entries for resistance to Rhizoctonia solani, and the root dry weight study

\begin{tabular}{|c|c|c|c|c|}
\hline Source of variation & df & MS & $\boldsymbol{F}$ & $P>F$ \\
\hline \multicolumn{5}{|c|}{ Ancestral lines (initial screen) ${ }^{\mathrm{a}}$} \\
\hline Trial & 1 & 20.987 & 38.11 & 0.0001 \\
\hline Block (trial) & 4 & 3.245 & 5.83 & 0.0001 \\
\hline Entry & 92 & 0.793 & 1.45 & 0.0088 \\
\hline Entry $\times$ trial & 92 & 0.589 & 1.09 & 0.2927 \\
\hline \multicolumn{5}{|c|}{ Ancestral lines (re-evaluation) ${ }^{\mathrm{b}}$} \\
\hline Trial & 1 & 13.896 & 27.43 & 0.0001 \\
\hline Block (trial) & 4 & 1.555 & 3.07 & 0.0180 \\
\hline Entry & 40 & 0.961 & 1.90 & 0.0028 \\
\hline Entry $\times$ trial & 40 & 0.567 & 1.12 & 0.3075 \\
\hline \multicolumn{5}{|c|}{ Commercial cultivar (stage 3$)^{\mathrm{c}}$} \\
\hline Trial & 1 & 108.654 & 440.69 & 0.0001 \\
\hline Block (trial) & 10 & 2.619 & 10.62 & 0.0001 \\
\hline Entry & 20 & 0.416 & 1.69 & 0.0385 \\
\hline Entry $\times$ trial & 20 & 0.326 & 1.32 & 0.1699 \\
\hline \multicolumn{5}{|l|}{ Root dry weight study ${ }^{\mathrm{d}}$} \\
\hline Trial & 1 & 0.682 & 190.69 & 0.0001 \\
\hline Entry & 20 & 0.010 & 2.70 & 0.0009 \\
\hline Entry $\times$ trial & 20 & 0.004 & 1.20 & 0.2795 \\
\hline
\end{tabular}

a In this study, 90 soybean lines and three check cultivars were arranged in a randomized complete block design (RCBD) with three blocks. The experiment was repeated.

${ }^{\mathrm{b}}$ In this study, 38 soybean lines and three check cultivars were arranged in an RCBD with 3 blocks. The experiment was repeated.

${ }^{\mathrm{c}}$ In this study, 19 commercial cultivars and two check cultivars were arranged in an RCBD with 6 blocks. The experiment was repeated.

${ }^{\mathrm{d}}$ The root dry weight study included 21 soybean cultivars arranged in a completely randomized design with 3 replications. The experiment was repeated.

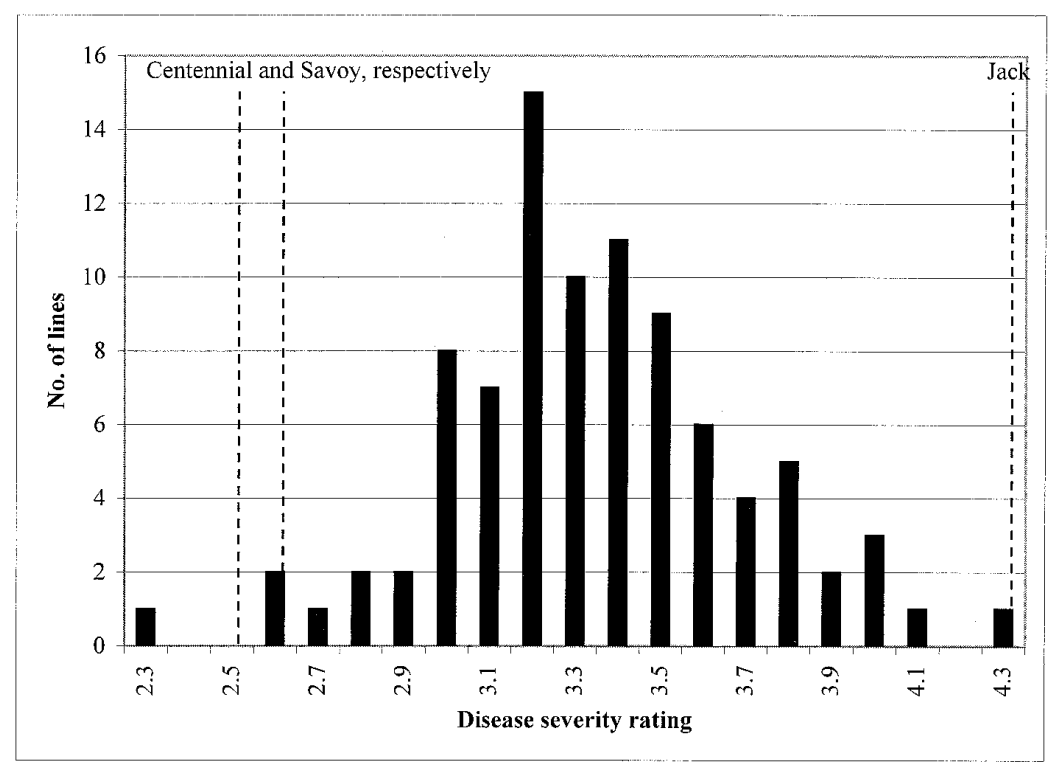

Fig. 1. Frequency distribution of Rhizoctonia root and hypocotyl rot ratings of 90 ancestral soybean lines and the mean severity ratings of the partially resistant (Centennial and Savoy) and susceptible (Jack) check cultivars. Data are combined from two trials.

Commercial cultivars. Seven hundred commercial cultivars (MGs II to IV) were obtained from the University of Illinois Variety Testing Program and were inoculated with $R$. solani using the same methods as previously described. All 700 cultivars (five seeds per cultivar) were evaluated in one experiment without replications. Cultivars with a mean disease severity rating at least 1.0 standard deviation (SD) below the grand mean for all 700 cultivars were advanced to the second stage of screening. In the second stage of screening, 140 cultivars and the check cultivars Jack and Savoy were evaluated for resistance to $R$. solani using the same methods as previously described. The cultivars were arranged in an RCB design with three replications, and the study was repeated. Cultivars that had a mean disease severity rating at least $1.0 \mathrm{SD}$ below the grand mean of the 140 cultivars in the second stage were advanced to the third stage of screening. For the third stage of screening, 19 cultivars, as well as Jack and Savoy, were re-evaluated using the same methods as previously described. The cultivars were arranged in an RCB design with six replications, and the study was repeated.

Root dry weight. An additional study was done using the 19 cultivars from the third stage of screening of the commercial cultivars to determine the effect of $R$. solani on root dry weight. Three seeds of each cultivar were planted in $1,000 \mathrm{~cm}^{3}$ polypropylene pots containing a steampasteurized potting mixture that consisted of a 2:1 ratio of sand to a silt loam soil, respectively. At growth stage VE, plants were thinned to one plant per pot. Plants were then either inoculated with $R$. solani using the method of inoculation described previously or not inoculated, which served as a control. Three weeks after inoculation, roots from both inoculated and noninoculated plants were removed from the pots, washed thoroughly under running tap water, dried for 1 week with forced air at $38^{\circ} \mathrm{C}$, and weighed. Root dry weight measurement data from each inoculated plant were converted to a percentage root dry weight of the noninoculated controls for that specific cultivar by: (inoculated root dry weight/mean noninoculated root dry weight of that specific cultivar) $* 100$. The experiment was arranged in a completely randomized design with three replications so that there were a total of 42 treatments (pots) per replication (21 cultivars $\times 2 R$. solani inoculated or noninoculated $=42$ ). The root dry weight study was repeated.

Data analysis. For the ancestral line and commercial cultivar screens, individual seedlings were evaluated using the disease severity scale. Line or cultivar means were calculated from the evaluated seedlings in each replication (five seedlings per replication) and were used for data analysis. In all replicated experiments, analysis of vari- 
ance (ANOVA) was conducted using the general linear models procedure (PROC GLM) of SAS (SAS Institute, Cary, NC). For the stages of screening, the data within each stage were pooled and analyzed together because there were no significant $(P$ $=0.05$ ) line or cultivar by trial interactions. The two root dry weight experiments also were analyzed together because there was not a significant $(P=0.05)$ trial by cultivar interaction. Means were compared using Fisher's protected least significant difference (LSD) at $P=0.05$. A Spearman's correlation coefficient was calculated between disease severity and percentage root dry weight of noninoculated controls for the root dry weight study using the SAS Spearman correlation procedure (PROC CORR SPEARMAN).

\section{RESULTS AND DISCUSSION}

There were no significant $(P=0.05)$ line or cultivar by trial interactions (Table 1 ); therefore data from each trial were pooled and analyzed together. The data from the root dry weight study were also pooled and analyzed together, since there was not a significant $(P=0.05)$ cultivar by trial interaction.

Ancestral lines. The mean disease severity for the initial screening of the ancestral lines was 3.3 compared with a mean of 4.3 for Jack (susceptible check), and 2.5 and 2.6 for Centennial and Savoy (partially resistant checks), respectively (Fig. 1). Thirty-eight of the lines had mean disease severity ratings ranging from 2.3 to 3.2 and were not significantly $(P=0.05)$ different from Centennial. In the re-evaluation of the most resistant ancestral lines, none were more resistant than Centennial, but 21 of the 38 lines tested had severity ratings not significantly different $(P=0.05)$ from Centennial (Table 2).

Of the 21 ancestral lines with the highest level of resistance, CNS, Mandarin (Ottawa), and Jackson are in the pedigree of public cultivars previously reported as being partially resistant to $R$. solani (15). For example, CNS is in the pedigree of Savoy, Hardee, Pella, and Centennial; Mandarin (Ottawa) is in the pedigree of Savoy and Pella; and Jackson is in the pedigree of Centennial. According to Gizlice et al. (8), CNS contributes $9 \%$ of the genetic background of the 258 North American public cultivars released between 1947 and 1988, Mandarin (Ottawa) contributes $12 \%$, and Jackson contributes $1 \%$. These three ancestral lines may represent sources of partial resistance to $R$. solani present in modern cultivars.

Commercial cultivars. The mean disease severity rating of commercial soybean cultivars was 3.5 , compared with ratings of 1.6 for Savoy and 4.0 for Jack. The 140 cultivars that were advanced to the second stage of screening had disease severities ranging from 0.2 to 2.4 . In the second stage screen, the mean severity of the 140 culti- vars was 3.3 compared with ratings of 2.2 for Savoy and 3.9 for Jack, and 19 cultivars were advanced to the third stage of screening. The range of disease severity ratings for the 19 cultivars was 1.9 to 2.3 (Fig. 2). In the third stage of screening, all 19 cultivars had significantly $(P=$ 0.05 ) lower disease ratings than Jack (susceptible), but none were more resis- tant than the partially resistant check Savoy (Table 3).

Companies breeding soybean currently do not breed for resistance to $R$. solani. Only six cultivars have been reported as sources of resistance to this disease (15), and only two of these cultivars are in MGs earlier than VI. One of the goals of this project was to identify commercial soy-

Table 2. Mean severity ratings of Rhizoctonia root and hypocotyl rot of 21 ancestral soybean lines and three soybean cultivars 3 weeks after inoculation with Rhizoctonia solani in the greenhouse ${ }^{\mathrm{a}}$

\begin{tabular}{lcc}
\hline Soybean entry & Maturity group & Mean severity rating \\
\hline PI84.946-2 & IV & 2.5 \\
Fiskeby V (PI360.955A) & 000 & 2.5 \\
CNS & IX & 2.6 \\
PI180.501 & 0 & 2.6 \\
Sioux & 000 & 2.6 \\
PI248.404 & 0 & 2.7 \\
PI171.450 & III & 2.7 \\
Sato & IV & 2.7 \\
Hahto & VI & 2.8 \\
Manitoba Brown & 00 & 2.9 \\
Improved Pelican & VIII & 3.0 \\
Bansei & II & 3.0 \\
Vance & V & 3.0 \\
PI171.451 & VII & 3.0 \\
Jackson & VII & 3.0 \\
Curtis & VI & 3.0 \\
Higan & IV & 3.0 \\
Habaro & I & 3.0 \\
Blackeye & 0 & 3.0 \\
Aoda & IV & 3.1 \\
Mandarin (Ottawa) & 0 & 3.1 \\
Centennial (partially resistant check) & VI & 2.5 \\
Savoy (partially resistant check) & II & 2.9 \\
Jack (susceptible check) & II & 4.0 \\
LSD (P = 0.05) & & 0.7 \\
Coefficient of variation (\%) & & 20 \\
\hline Da represent mans from & &
\end{tabular}

${ }^{a}$ Data represent means from two trials combined for analysis.

${ }^{\mathrm{b}}$ Roots and hypocotyl were examined together and given one severity rating using a 0 to 5 scale where $0=$ no lesions, $1=$ lesions $<2.5 \mathrm{~mm}, 2=$ lesions 2.5 to $5 \mathrm{~mm}, 3=$ lesions $>5 \mathrm{~mm}, 4=$ lesions girdling plant and wilting visible on leaves, and $5=$ seedlings damped-off or dead.

${ }^{\mathrm{c}}$ Fisher's protected least significant difference (LSD).

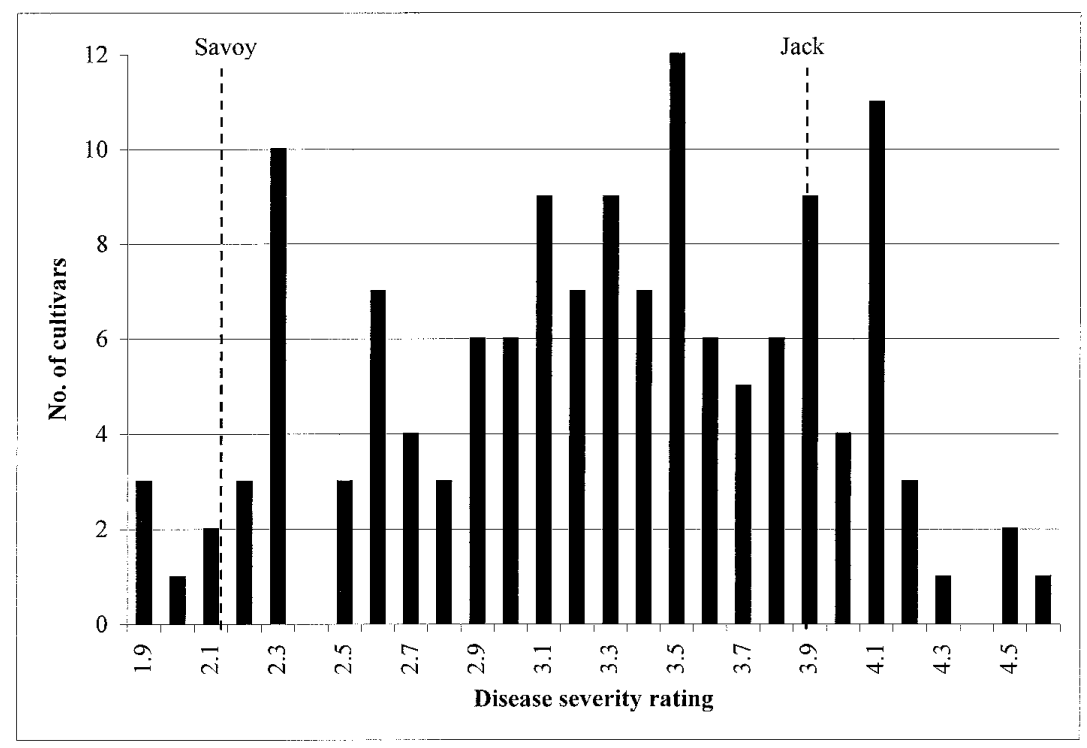

Fig. 2. Frequency distribution of Rhizoctonia root and hypocotyl rot ratings of 140 commercial soybean cultivars and the mean severity ratings of the partially resistant (Savoy) and susceptible (Jack) check cultivars in the second stage of screening. 
bean cultivars in MGs II to IV that display resistance to $R$. solani, so that growers and the seed industry would have sources of resistance for managing Rhizoctonia root and hypocotyl rot. Based on the results from this study, most of the commercial soybean cultivars tested were susceptible to Rhizoctonia root and hypocotyl rot. The final 19 commercial cultivars selected plus the moderately resistant check Savoy appear to be the best sources of resistance to $R$. solani in commercial cultivars entered in the University of Illinois Variety Testing Program.

Sixteen of the 19 most resistant commercial cultivars had purple hypocotyls; only Dekalb CX339C, LG Seeds 6457, and Pioneer 93B51 had white hypocotyls. The partially resistant check Savoy has purple hypocotyls, while the susceptible check Jack has white hypocotyls. Although dark pigments have not been reported as being linked to resistance to $R$. solani in soybean, many researchers have indicated that dark pigments located in the seed coat or hypocotyl may be linked to resistance to $R$. solani in Phaseolus vulgaris L. $(5,12,14,19-21)$.

Root dry weight. There were significant differences among cultivars for root dry weight expressed as a percentage of the noninoculated controls, and percentages ranged from 37 to $88 \%$ (Table 3). Even though a cultivar may have partial resistance, based on the disease severity scale,

Table 3. Mean severity ratings of Rhizoctonia root and hypocotyl rot and percentage of root dry weight for 21 commercial soybean cultivars inoculated with Rhizoctonia solani in the greenhouse ${ }^{\mathrm{a}}$

\begin{tabular}{lccc}
\hline Soybean cultivar & Maturity group & $\begin{array}{c}\text { Mean severity } \\
\text { rating }^{\mathbf{b}}\end{array}$ & $\begin{array}{c}\text { Mean root dry wt } \\
\text { (\% noninoculated) }\end{array}$ \\
\hline Asgrow 2601 & II & 2.5 & 64 \\
Trisler 3252 & III & 2.6 & 55 \\
Asgrow 3702 & III & 2.7 & 57 \\
Pioneer 93B84 & III & 2.8 & 50 \\
Trisler 2997 & II & 2.8 & 59 \\
LG Seeds 6457 & IV & 2.9 & 88 \\
Growmark HS 2861 & II & 2.9 & 52 \\
Excel 8320 & III & 2.9 & 85 \\
Agripro 3009 & III & 3.0 & 37 \\
Trisler 2880 & II & 3.0 & 68 \\
Daraedt 2655 & II & 3.0 & 44 \\
Trisler 2770 & II & 3.0 & 65 \\
Crow's 36009 & III & 3.0 & 68 \\
Cargill B395 & III & 3.0 & 64 \\
Kruger 3131 & III & 3.1 & 59 \\
Crow's 32003 & III & 3.1 & 42 \\
Dekalb CX339C & III & 3.2 & 73 \\
Kruger 3333 & III & 3.2 & 59 \\
Pioneer 93B51 & III & 3.3 & 71 \\
Savoy (partially resistant check) & II & 2.5 & 47 \\
Jack (susceptible check) & II & 4.4 & 81 \\
Mean & & 3.0 & 61 \\
LSD $(P=0.05)$ & & 0.7 & 23 \\
Coefficient of variation (\%) & & 25 & 23 \\
\hline Data & & &
\end{tabular}

${ }^{a}$ Data represent means from two trials combined for analysis; mean disease severity ratings and mean root dry weights are from separate experiments.

${ }^{\mathrm{b}}$ Roots and hypocotyl were examined together and given one severity rating using a 0 to 5 scale where $0=$ no lesions, $1=$ lesions $<2.5 \mathrm{~mm}, 2=$ lesions 2.5 to $5 \mathrm{~mm}, 3=$ lesions $>5 \mathrm{~mm}, 4=$ lesions girdling plant and wilting visible on leaves, and $5=$ seedlings damped-off or dead.

${ }^{\mathrm{c}}$ Percentage of noninoculated root dry weight from greenhouse experiments was calculated by: (inoculated root dry weight/mean noninoculated root dry weight) $* 100$.

d Fisher's protected least significant difference (LSD). when testing cultivars for root and hypocotyl resistance against $R$. solani AGs 2-2 and 4 . They also reported that three cultivars exhibited partially resistant responses to the root and hypocotyl rot isolates (AGs 2-2 and 4) and the web blight isolates (AG 1). Soybean lines and cultivars in this study were tested against only one highly aggressive isolate of $R$. solani AG 2-2. More research is needed to confirm if the soybean lines and cultivars reported as having partial resistance in this study have resistance to $R$. solani across additional AGs.

The mechanism of resistance in soybean to $R$. solani is not known. Stockwell and Hanchey (23) reported that in Phaseolus vulgaris, increased calcification of cell walls and increased cuticle thickness were important factors in resistance to $R$. solani. Further research is needed to determine if these factors play a role in the partial resistance found in soybean cultivars and to determine the nature of inheritance of this partial resistance.

\section{ACKNOWLEDGMENTS}

We thank the Soybean Research and Development Council and the Illinois Soybean Program Operating Board for partial funding of this project, and K. Ames, R. Warsaw, and C. Weeks for technical assistance.

\section{LITERATURE CITED}

1. Baird, R. E., Carling, D. E., and Mullinix, B. G. 1996. Characterization and comparison of isolates of Rhizoctonia solani AG-7 from Arkansas, Indiana, and Japan, and select AG-4 isolates. Plant Dis. 80:1421-1424.

2. Cardoso, J. E., and Echandi, E. 1987. Biological control of Rhizoctonia root rot of snap bean with binucleate Rhizoctonia-like fungi. Plant Dis. 71:167-170.

3. Cardoso, J. E., Hildebrandt, A. C., and Grau, C. R. 1978. Evaluation of soybean germplasm for resistance to Rhizoctonia solani $\mathrm{Kuhn}$. Fitopatol. Bras. 3:205-209.

4. Carling, D. E., Rothrock, C. S., MacNish, G. C., Sweetingham, M. W., Brainard, K. A., and Winters, S. W. 1994. Characterization of anastomosis group 11 (AG-11) of Rhizoctonia solani. Phytopathology 84:1387-1393.

5. Deakin, J. R., and Dukes, P. D. 1975. Breeding snap beans for resistance to diseases caused by Rhizoctonia solani Kuehn. HortScience 10:269-271.

6. Engelkes, C. A., and Windels, C. E. 1996. Susceptibility of sugar beet and beans to Rhizoctonia solani AG-2-2 IIIB and AG-2-2 IV. Plant Dis. 80:1413-1417.

7. Fehr, W. R., Caviness, C. E., Burmood, D. T., and Pennington, J. S. 1971. Stage of development descriptions for soybeans, Glycine $\max ($ L.) Merrill. Crop Sci. 11:929-931.

8. Gizlice, Z., Carter, T. E., and Burton, J. W. 1994. Genetic base for North American public soybean cultivars released between 1947 and 1988. Crop Sci. 34:1143-1151.

9. Hwang, S., Howard, R. J., and Chang, K. 1996. Forage and oilseed legume diseases incited by Rhizoctonia species. Pages 289-301 in: Rhizoctonia Species: Taxonomy, Molecular Biology, Ecology, Pathology and Disease Control. B. Sneh, S. Jabaji-Hare, S. Neate, and G. Dijst, eds. Kluwer Academic Publishers, Dordrecht, Netherlands.

10. Lewis, J. A., and Papavizas, G. C. 1977. Factors affecting Rhizoctonia solani infection 
of soybeans in the greenhouse. Plant Dis. Rep. 61:196-200.

11. Liu, Z., and Sinclair, J. B. 1991. Isolates of Rhizoctonia solani anastomosis group 2-2 pathogenic to soybean. Plant Dis. 75:682687.

12. McLean, D. M., Hoffman, J. C., and Brown, G. B. 1968. Greenhouse studies on resistance of snap beans to Rhizoctonia solani. Plant Dis. Rep. 52:486-488.

13. Meyer, L., Wehner, F. C., Nel, L. H., and Carling, D. E. 1998. Characterization of the crater disease strain of Rhizoctonia solani. Phytopathology 88:366-371.

14. Moody, A. R., Benepal, P. S., and Berkley, B. 1980. Resistance of Phaseolus vulgaris L. cultivars to hypocotyl inoculation with Rhizoctonia solani Kuehn. J. Am. Hortic. Sci. 105:836-838.

15. Muyolo, N. G., Lipps, P. E., and Schmitthenner, A. F. 1993. Reactions of dry bean, lima bean, and soybean cultivars to Rhizoctonia root and hypocotyl rot and web blight. Plant Dis. 77:234-238

16. Muyolo, N. G., Lipps, P. E., and Schmitthen- ner, A. F. 1993. Anastomosis grouping and variation in virulence among isolates of Rhizoctonia solani associated with dry bean and soybean in Ohio and Zaire. Phytopathology 83:438-444.

17. Nelson, B., Helms, T., Christianson, T., and Kural, I. 1996. Characterization and pathogenicity of Rhizoctonia from soybean. Plant Dis. 80:74-80.

18. Phillips, A. J. L. 1991. Variation in virulence to dry beans, soybeans and maize among isolates of Rhizoctonia solani from beans. Ann. Appl. Biol. 118:9-17.

19. Prasad, K., and Weigle, J. L. 1969. Resistance to Rhizoctonia solani in Phaseolus vulgaris (snap bean). Plant Dis. Rep. 53:350-352.

20. Prasad, K., and Weigle, J. L. 1970. Screening for resistance to Rhizoctonia solani in Phaseolus vulgaris. Plant Dis. Rep. 54:40-44.

21. Prasad, K., and Weigle, J. L. 1976. Association of seed coat factors with resistance to Rhizoctonia solani in Phaseolus vulgaris. Phytopathology 66:342-345.

22. Rizvi, S. S. A., and Yang, X. B. 1996. Fungi associated with soybean seedling disease in
Iowa. Plant Dis. 80:57-60.

23. Stockwell, V., and Hanchey, P. 1984. The role of the cuticle in resistance of beans to Rhizoctonia solani. Phytopathology 74:1640-1642.

24. Tachibana, H., Jowett, D., and Fehr, W. R. 1971. Determination of losses in soybeans caused by Rhizoctonia solani. Phytopathology 61:1444-1446.

25. Wrather, J. A., Anderson, T. R., Arsyad, D. M., Gai, J., Ploper, L. D., Porta-Puglia, A. Ram, H. H., and Yorinori, J. T. 1997. Soybean disease loss estimates for the top 10 soybean producing countries in 1994. Plant Dis. 81:107-110.

26. Wrona, A. F., VanderMolen, G. E., and DeVay, J. E. 1981. Trifluralin-induced changes in hypocotyls of Phaseolus vulgaris in relation to lesion development caused by Rhizoctonia solani Kühn. Physiol. Plant Pathol. 18:99106.

27. Yang, X. B. 1999. Rhizoctonia damping-off and root rot. Pages 45-46 in: Compendium of Soybean Diseases. 4th ed. G. L. Hartman, J. B. Sinclair, and J. C. Rupe, eds. American Phytopathological Society, St. Paul, MN. 